\title{
Association between MTHFR genetic polymorphism and Parkinson's disease susceptibility: a meta-analysis
}

https://doi.org/10.1515/med-2019-0069

received May 13, 2019; accepted June 27, 2019

\begin{abstract}
Folate metabolism plays quite a critical role in Parkinson's disease (PD). Previous published research works have studied the link existing between the folate metabolism genetic polymorphisms and PD susceptibility; nevertheless, the results continue having controversies and inconclusiveness. Accordingly, we carried out the present meta-analysis for the assessment of the potential link between the folate metabolism genetic polymorphisms and the susceptibility to PD. In addition we carried out a literature search in the PubMed, EMBASE, Cochrane Library, and WanFang databases till November 10, 2018. The odds ratios (ORs) with corresponding 95\% credible interval $(95 \% \mathrm{CI})$ were put to use for evaluating the strength of the association of three folate metabolism genetic polymorphism (C677T, A1298C, and A2756G) with the susceptibility to PD. Each statistical analysis was carried out with the use of STATA 15.0. An aggregate of twenty-one case-control investigations were retrieved, which involved 3,944 PD patients and 4,412 controls. We discovered the existence of no substantial link between the C677T and A1298C polymorphism and PD risk in any genetic framework comparisons. With regard to A2756G polymorphism, we discovered that there was an association between the A2756G genetic polymorphism and an augmented threat of PD in the co-dominant genetic framework (GG vs. AA: OR=1.86, 95\%CI=1.02-3.37, $\mathrm{P}=0.042$ ) and the recessive genetic model (GG vs. $\mathrm{GA}+\mathrm{AA}: \mathrm{OR}=1.90$, 95\%CI=1.06-3.41, $\mathrm{P}=0.031$ ). To summarize, our research work indicates that the $\mathrm{A} 2756 \mathrm{G}$ polymorphism of the folate metabolism gene had an association with an augmented
\end{abstract}

*Corresponding author: Hai-Dong Xu,Department of Neurology, the Central People's Hospital of Tengzhou City, Tengzhou 277500, Shandong, China, E-mail: xuhaidong3636@163.com

Hong-Mei Diao, Zheng-Feng Song, Department of Neurology, the Central People's Hospital of Tengzhou City, Tengzhou 277500, Shandong, China threat of PD. Also, A1298C polymorphisms is unlikely to significantly contribute towards the susceptibility to PD. Further large-scale case-control studies are still required.

Keywords: Parkinson's disease; MTHFR; MTR; Polymorphism; Meta-analysis

\section{Introduction}

Parkinson's disease (PD) is termed as the second most frequently prevalent neurodegenerative disorder following the Alzheimer's disease, which impacts approximately $1 \%$ of the individuals aged more than 60 across the globe and $4-5 \%$ of people aged more than 85 years $[1,2]$. Clinically, $\mathrm{PD}$ is manifested by the classical motor symptoms, which include not only the tremor, but also the rigidity, bradykinesia, and postural instability, significantly impacting the patients' quality of life $[2,3]$. These medicinal presentations constitute the results of dopaminergic neuron loss in the substantia nigra, leading the lowered degrees of dopamine in the striatum and disrupted motor control. Despite the fact that the reason leading to the neuronal loss is not clear, more and more evidence has suggested that mitochondrial impairment, endothelial damage, inflammatory process, and oxidative stress are considered as playing key roles when it comes to the selective dopaminergic cell death in the brain of those patients, who have $\mathrm{PD}[4,5]$.

Homocysteine (Hcy) has been observed as enhancing mitochondrial dysfunction, apoptosis, and oxidative stress, together with being a contributing determinant in the pathophysiological process to a number of neurodegenerative diseases that include $\mathrm{PD}[6,7]$. Hcy is a sulfur-containing amino acid, which is derived from the demethylation of methionine by means of the methionine cycle and the folate cycle [8]. Methylenetetrahydrofolate reductase (MTHFR) is a folate-reliant enzyme that cata- 
lyzes 5,10-methylenetetrahydrofolate to 5-methyltetrahydrofolate. The output is termed as the dominant form of circulating folate, besides providing a methyl group for the re-methylation of Hcy back to methionine [8]. Three common variants (C677T, A1298C, and A2756G) in the MTHFR gene, which lower the function of MTHFR, in addition to further resulting into the metabolic disruption of Hcy, have been indicated as having association with the risk of patients with PD $[8,9]$.

A number of case-control investigations have explored the potential link that exists between the MTHFR genetic polymorphisms and susceptibility to PD, but the findings are still inconclusive [9-12]. Hence, we carried out the present meta-analysis in order to clarify the link existing between the MTHFR polymorphisms and susceptibility to PD with the use of qualified data attained from the published case-control research works.

\section{Materials and methods}

The current meta-analysis was carried out in accordance with the consensus statement of the Meta-analysis of Observational Studies in Epidemiology recommendations [13]. All the analysis was carried out on the basis of previously published works; in this manner, ethical approval and patient consent were not required.

\subsection{Identification of eligible studies}

A literature search in the PubMed, as well as in the EMBASE, Cochrane Library, and WanFang databases was carried out to figure out the eligible studies, and the latest search was updated in November 2018. The terms presented as follows, together with their combinations,

\section{PRISMA 2009 Flow Diagram}
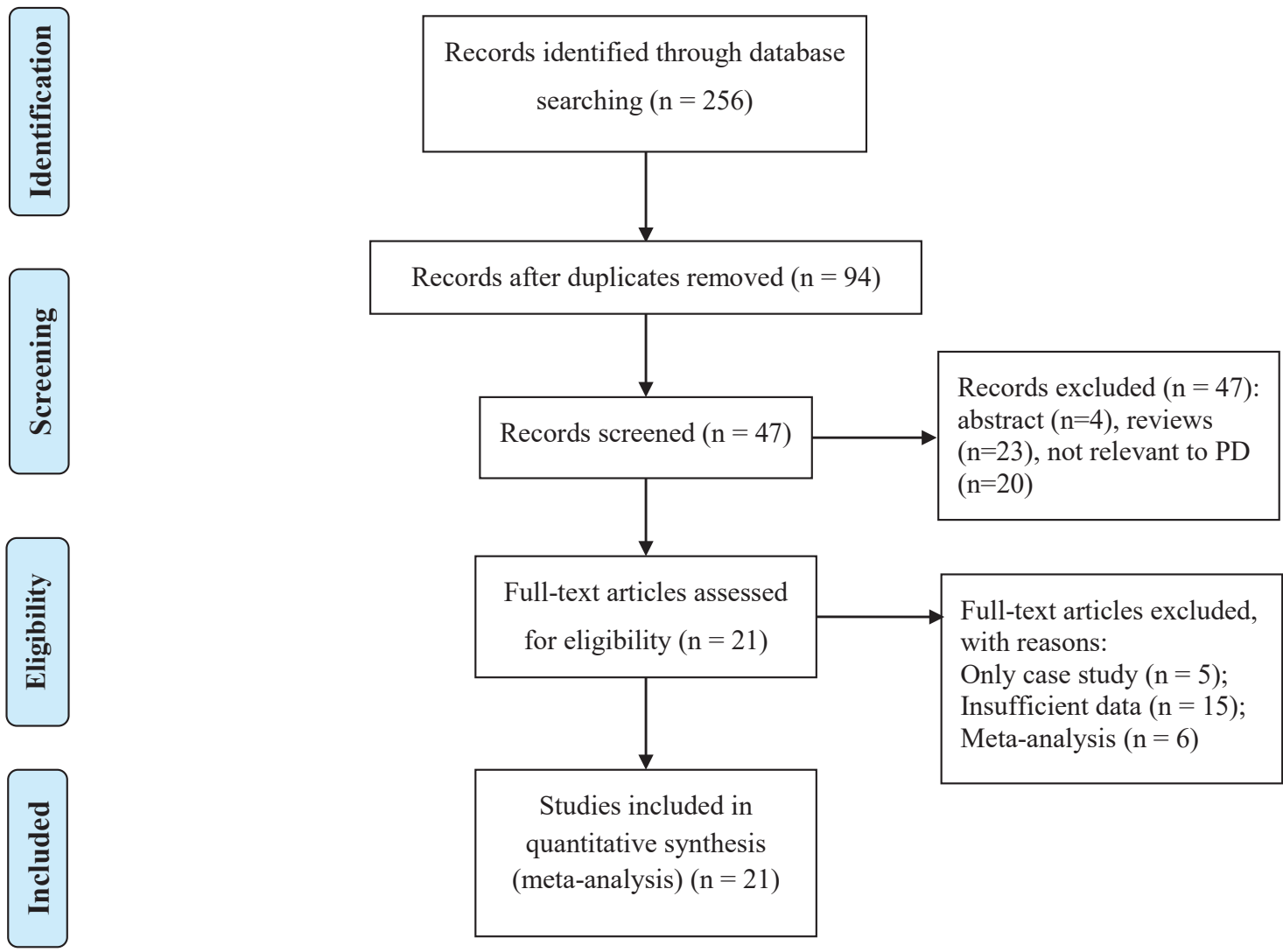

Figure 1: Flow diagram of included and excluded studies. 

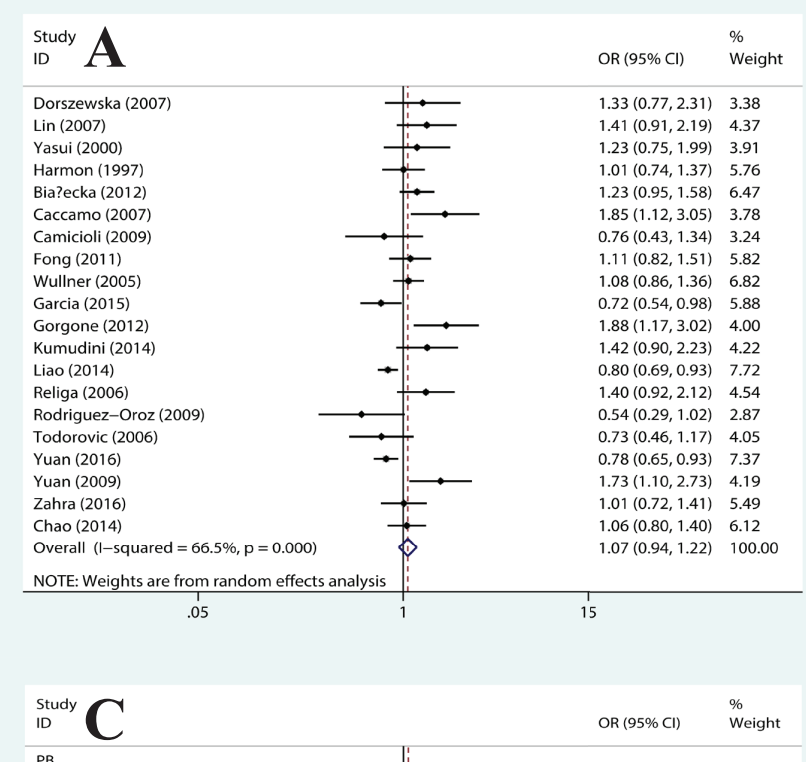

PB Lin (2007)
Yasui (2000) Harmon (1997)
Caccamo (2007) Garcia (2015) Gorgone (2012)
Kumudini (2014 Liao (2014) Rodriguez-Oroz (2009) Todorovic (2006)
Yuan (2016) Zahra (2016) Subtotal (I-squared $=69.6 \%, \mathrm{p}=0.000$ ) HB
Bia?ecka (2012) Camicioli (2009)
Fong (2011) Rong (2011) Yuan (2009) Chao (2014)

Subtotal (I-squared $=22.5 \%, p=0.265)$

Overall (I-squared $=67.8 \%, p=0.000$ ) NOTE: Weights are from random effects analysis .05
OR $(95 \%$ Cl) $\quad$ Weight $1.33(0.77,2.31) \quad 3.72$ $1.41(0.91,2.19) \quad 4.74$ $\begin{array}{ll}1.41 \\ 1.01(0.74,1.37) & 6.14 \\ 1.85(1.12,05) & 4.14\end{array}$ $\begin{array}{ll}1.85(1.12,3.05) & 4.14 \\ 0.72(0.54,0.98) & 6.26\end{array}$ $\begin{array}{ll}0.72(0.54,0.98) & 6.26 \\ 1.88(1.17,3.02) & 4.36\end{array}$ $1.88(1.17,3.02) \quad 4.36$ $1.42(0.90,2.23) \quad 4.59$ $0.80(0.69,0.93) \quad 8.02$ $0.73(0.46,1.17) \quad 4.42$ $1.01(0.72,1.41) \quad 5.87$ $1.03(0.86,1.22) \quad 67.42$

$1.23(0.95,1.58) \quad 6.84$ . $.76(0.43,1.34) \quad 3.58$ $1.40(0.92,2.12) \quad 4.92$ $\begin{array}{ll}1.06(0.80,1.40) & 6.49 \\ 1.18(1.01,1.39) & 32.58\end{array}$

$1.18(1.01,1.39) \quad 32.58$

$1.07(0.93,1.23) \quad 100.00$ $1.73(1.10,2.73) \quad 4.56$
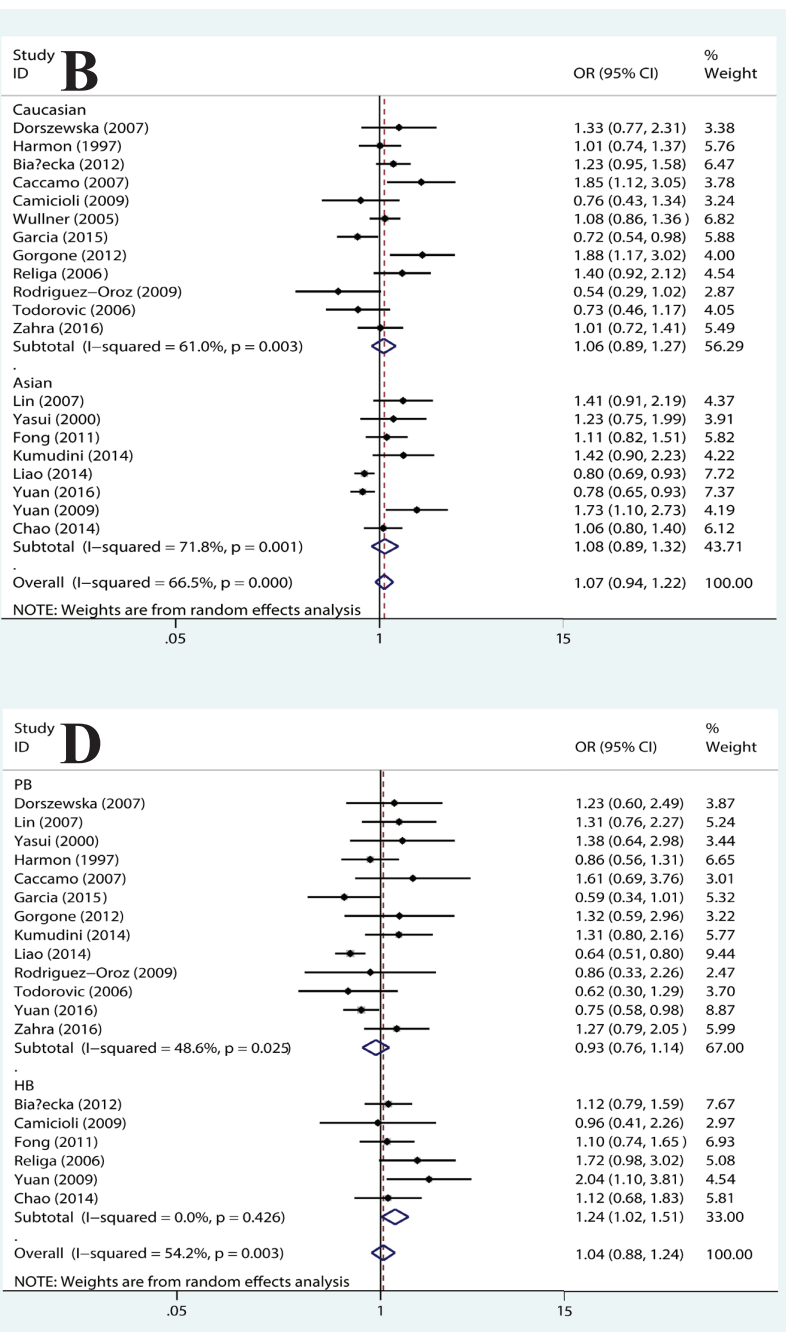

Figure 2: Forest plot of the association between MTHFR C677T polymorphism and PD susceptibility: (A) allelic genetic model in the overall populations; (B) allelic genetic model, stratified by ethnicity; (C) allelic and (D) co-dominant genetic model, stratified by source of control.

were searched: 'methylenetetrahydrofolate reductase' OR 'MTHFR' AND 'Parkinson's disease' OR 'PD' AND 'polymorphism ${ }^{\star}$ ' OR 'variant ${ }^{\star}$. Each of the search was constrained to English or Chinese language papers.

\subsection{Inclusion and exclusion}

The qualified research works mandatorily require meeting the inclusion criteria as hereunder: (1) evaluate the link existing between the MTHFR polymorphisms and susceptibility to PD; (2) case-control research design; (3) enough amount of data for the calculation of the odds ratios (ORs), coupled with 95 percent confidence interval (95\%CI). The research works were not counted on for any of the following reasons: (1) inadequate amount of information for extracting the data; (2) only case study; (3) case reports, reviews, letters; (4) studies carried out in non-humans, and duplicated publication. For the research works having copied data, the biggest or the latest publication was chosen.

\subsection{Data extraction}

All data were independently extracted by two investigators in accordance with the above-mentioned inclusion criteria. Moreover, the following information was extracted from all of the research works included: the first author, in addition to the year of publication, country, ethnicity, genotype distributions in cases as well as controls, besides the detection methodology of genotypes. The disagreement existing between scholars were removed through the consultation with a $3^{\text {rd }}$ scholar. 
Table 1: Main characteristics of included studies in this meta-analysis.

\begin{tabular}{|c|c|c|c|c|c|c|c|c|}
\hline Author & Year & Country & Ethnicity & $\begin{array}{l}\text { Control } \\
\text { Source }\end{array}$ & $\begin{array}{l}\text { Sample Size } \\
\text { Case }\end{array}$ & Control & $\begin{array}{l}\text { Genotyping } \\
\text { Methods }\end{array}$ & $\begin{array}{l}\text { HWE in } \\
\text { controls }\end{array}$ \\
\hline Dorszewska & 2007 & Poland & Caucasian & PB & 98 & 50 & PCR-RFLP & 0.495 \\
\hline Lin & 2007 & China & Asian & PB & 94 & 146 & PCR-RFLP & 0.410 \\
\hline Yasui & 2000 & Japan & Asian & PB & 90 & 53 & PCR & 0.194 \\
\hline Harmon & 1997 & Ireland & Caucasian & PB & 188 & 184 & PCR & 0.132 \\
\hline Białecka & 2012 & Poland & Caucasian & $\mathrm{HB}$ & 320 & 254 & PCR-RFLP & 0.855 \\
\hline Caccamo & 2007 & Italy & Caucasian & PB & 49 & 86 & PCR & 0.376 \\
\hline Camicioli & 2009 & Canada & Caucasian & $\mathrm{HB}$ & 51 & 49 & PCR & 0.804 \\
\hline Fong & 2011 & China & Asian & $\mathrm{HB}$ & 211 & 218 & PCR & 0.494 \\
\hline Wullner & 2005 & Germany & Caucasian & NA & 342 & 342 & PCR & 0.021 \\
\hline Garcia & 2015 & Mexico & Caucasian & PB & 140 & 216 & TaqMan & 0.118 \\
\hline Gorgone & 2012 & Italy & Caucasian & PB & 60 & 82 & PCR & 0.430 \\
\hline Kumudini & 2014 & India & Asian & PB & 151 & 416 & PCR-RFLP & 0.352 \\
\hline Liao & 2014 & China & Asian & PB & 765 & 717 & PCR & 0.013 \\
\hline Religa & 2006 & Poland & Caucasian & $\mathrm{HB}$ & 114 & 100 & PCR & 0.901 \\
\hline Rodriguez-Oroz & 2009 & Spain & Caucasian & PB & 77 & 28 & PCR-RFLP & 0.748 \\
\hline Todorovic & 2006 & Serbia & Caucasian & PB & 113 & 53 & PCR & 0.583 \\
\hline Yuan & 2016 & China & Asian & PB & 512 & 512 & PCR & 0.347 \\
\hline Yuan & 2009 & China & Asian & $\mathrm{HB}$ & 76 & 110 & PCR-RFLP & 0.652 \\
\hline Zahra & 2016 & Malta & Caucasian & PB & 100 & 311 & PCR & 0.382 \\
\hline Chao & 2014 & China & Asian & $\mathrm{HB}$ & 161 & 240 & PCR & 0.198 \\
\hline Momose & 2002 & Japan & Asian & PB & 232 & 245 & PCR & 0.849 \\
\hline
\end{tabular}

Abbreviations: HWE, Hardy-Weinberg equilibrium; PCR-RFLP, Polymerase chain reaction-restriction fragment length polymorphism; PB, Population-based; HB, Hospital-based.

\subsection{Statistical analysis}

The Hardy-Weinberg equilibrium (HWE) was calculated by the Chi-squared test in control groups in all of the research works; the P-value more than 0.001 demonstrated that the population was in genetic equilibrium. Besides that, the odds ratios (ORs) that had 95 percent confidence interval (CI) were adopted for the purpose of calculating the strength of the link between PD susceptibility and the MTHFR polymorphisms. The importance associated with the accumulated OR was investigated in accordance with the Z-test; in addition, $P<0.05$ was regarded as having statistical significance. The evaluation of the between-study heterogeneity was carried out with the help of the Q-test as well as $I^{2}$ statistics [14]. Moreover, the application of the fixed-effects framework was made at $P_{\mathrm{h}}>0.1$ or $\mathrm{I}^{2}<50 \%$ [15]; or else, the random-effects framework was followed [16]. The sensitivity analysis was carried out through the omission of the single research work always for the evaluation of the robustness of the findings. Also, the underlying publication partiality was assessed with the help of the Begg's funnel plots and Egger's test [17, 18]. All of the sta- tistical analysis was carried out with the use of the STATA version 15.0 software (Stata Corporation, College Station, TX, USA). A $P$-value below 0.05 was regarded as having statistical significance.

\section{Results}

\subsection{Study characteristics}

The flow chart presented in Figure 1 shed light on the research selection mechanism. An aggregate of 256 papers were figured out by means of the preliminary search of databases. In accordance with the inclusion and exclusion criteria presented earlier, an aggregate of 21 case-control research works, which involved 3,944 PD patients and 4,412 controls, were included [10-12, 19-36]. Among the selected studies, 20 studies involving 3,712 PD patients and 4,167 controls were carried out for the purpose of evaluating MTHFR C677T polymorphism [10-12, 19-35]; 10 studies were carried out for the assessment of MTHFR 
Table 2: Summary ORs and $95 \% \mathrm{Cl}$ of the association between C677T polymorphism and Parkinson disease susceptibility.

\begin{tabular}{|c|c|c|c|c|c|c|c|c|}
\hline \multirow[t]{2}{*}{ Genetic models } & \multirow[t]{2}{*}{ Study subjects } & \multirow{2}{*}{$\begin{array}{l}\text { No. of } \\
\text { studies }\end{array}$} & \multirow{2}{*}{ OR $(95 \% \mathrm{Cl})$} & \multirow[t]{2}{*}{$p$-meta } & \multicolumn{2}{|c|}{ Test of heterogeneity } & \multirow[b]{2}{*}{ Model } & \multirow{2}{*}{$\begin{array}{l}\text { Test of } \\
\text { Egger's }\end{array}$} \\
\hline & & & & & $I^{2}(\%)$ & $p$-value & & \\
\hline \multirow[t]{5}{*}{ Tvs. C } & Overall & 20 & $1.07(0.94-1.22)$ & 0.297 & 66.5 & $<0.001$ & $\mathrm{R}$ & 0.206 \\
\hline & Asian & 8 & $1.08(0.89-1.32)$ & 0.429 & 71.8 & 0.001 & $R$ & \\
\hline & Caucasian & 12 & $1.06(0.89-1.27)$ & 0.497 & 61.0 & 0.003 & $\mathrm{R}$ & \\
\hline & PB & 13 & $1.03(0.86-1.22)$ & 0.781 & 69.6 & $<0.001$ & $\mathrm{R}$ & \\
\hline & $\mathrm{HB}$ & 6 & $1.18(1.01-1.39)$ & 0.043 & 22.5 & 0.265 & $\mathrm{R}$ & \\
\hline \multirow[t]{5}{*}{ TC vs. CC } & Overall & 20 & $1.06(0.90-1.25)$ & 0.494 & 56.3 & 0.001 & $\mathrm{R}$ & 0.581 \\
\hline & Asian & 8 & $1.06(0.81-1.40)$ & 0.676 & 70.9 & 0.001 & $\mathrm{R}$ & \\
\hline & Caucasian & 12 & $1.09(0.90-1.30)$ & 0.377 & 23.4 & 0.213 & $\mathrm{R}$ & \\
\hline & PB & 13 & $0.93(0.76-1.14)$ & 0.491 & 48.6 & 0.025 & $\mathrm{~F}$ & \\
\hline & $\mathrm{HB}$ & 6 & $1.24(1.02-1.51)$ & 0.034 & 0 & 0.426 & $\mathrm{~F}$ & \\
\hline \multirow[t]{5}{*}{ TT vs. CC } & Overall & 20 & $1.08(0.83-1.42)$ & 0.567 & 58.6 & 0.001 & $\mathrm{R}$ & 0.064 \\
\hline & Asian & 8 & $1.07(0.74-1.54)$ & 0.719 & 53.9 & 0.034 & $R$ & \\
\hline & Caucasian & 12 & $1.05(0.70-1.57)$ & 0.812 & 62.3 & 0.002 & $R$ & \\
\hline & PB & 13 & $1.03(0.70-1.52)$ & 0.878 & 66.3 & $<0.001$ & $\mathrm{R}$ & \\
\hline & $\mathrm{HB}$ & 6 & $1.30(0.96-1.77)$ & 0.094 & 0 & 0.469 & $\mathrm{R}$ & \\
\hline \multirow[t]{5}{*}{ TT+TC vs. CC } & Overall & 20 & $1.08(0.91-1.29)$ & 0.386 & 64.6 & $<0.001$ & $\mathrm{R}$ & 0.075 \\
\hline & Asian & 8 & $1.09(0.82-1.45)$ & 0.547 & 75.3 & $<0.001$ & $\mathrm{R}$ & \\
\hline & Caucasian & 12 & $1.09(0.88-1.34)$ & 0.442 & 45.0 & 0.045 & $\mathrm{R}$ & \\
\hline & PB & 13 & $0.98(0.78-1.22)$ & 0.842 & 63.5 & 0.001 & $\mathrm{R}$ & \\
\hline & $\mathrm{HB}$ & 6 & $1.27(1.03-1.55)$ & 0.023 & 11.5 & 0.342 & $\mathrm{R}$ & \\
\hline \multirow[t]{5}{*}{ TT vs. $\mathrm{CC}+\mathrm{CT}$} & Overall & 20 & $1.06(0.86-1.30)$ & 0.942 & 43.3 & 0.021 & $\mathrm{~F}$ & 0.186 \\
\hline & Asian & 8 & $0.99(0.79-1.24)$ & 0.926 & 15.5 & 0.308 & $\mathrm{R}$ & \\
\hline & Caucasian & 12 & $1.04(0.74-1.47)$ & 0.814 & 55.9 & 0.009 & $\mathrm{R}$ & \\
\hline & PB & 13 & $1.07(0.78-1.45)$ & 0.690 & 56.6 & 0.006 & $\mathrm{R}$ & \\
\hline & $\mathrm{HB}$ & 6 & $1.17(0.88-1.54)$ & 0.283 & 0 & 0.557 & $\mathrm{R}$ & \\
\hline
\end{tabular}

Abbreviations: Bold values indicate statistically significant results; OR, Odds ratio; $\mathrm{Cl}$, Confidence interval; $p$-meta, $p$-value of pooled effect; R, Random-effect model; F, Fixed-effect model;

A1298C polymorphism with an aggregate of 1,861 PD patients, together with 1,987 controls [12, 19, 23-25, 27, 31, 33, 34, 36]; 4 research works that contained $541 \mathrm{PD}$ patients as well as 709 controls, were performed for the purpose of evaluating MTHFR A2756G polymorphism [19, $26,29,31]$. Moreover, the key attributes of all of the investigations and HWE examination results were presented in Table 1 . The allocations of the MTHFR genetic mutation in controls were observed as showing consistency with HWE in all studies $(\mathrm{P}>0.001)$.

\subsection{MTHFR C677T and PD Susceptibility}

With regard to the MTHFR C677T polymorphism, as revealed by the meta-analysis, there was no statistically significant association in any of the genetic frameworks in the population, in general (Figure 2A). For the stratification in accordance with ethnicity, no substantial link in any of the genetic frameworks in Caucasians or Asians (Figure 2B) was observed. In the meantime, we conducted the stratified analysis in accordance with the source of controls, substantially augmenting the risk of PD discovered in the allelic genetic framework (T vs. C: $\mathrm{OR}=1.18,95 \% \mathrm{CI}=1.01-1.39, \mathrm{P}=0.043)$, co-dominant genetic framework (TC vs. CC: $\mathrm{OR}=1.24,95 \% \mathrm{CI}=1.02-1.51, \mathrm{P}=0.034$ ), and dominant genetic framework (TT+TC vs. $\mathrm{CC}: \mathrm{OR}=1.27$, 95\% CI=1.03-1.55, $\mathrm{P}=0.023$ ) in the hospital-based study (Figure $2 \mathrm{C}$ and 2D). Table 2 summarizes the meta-analysis findings between MTHFR C677T polymorphism and PD susceptibility. 


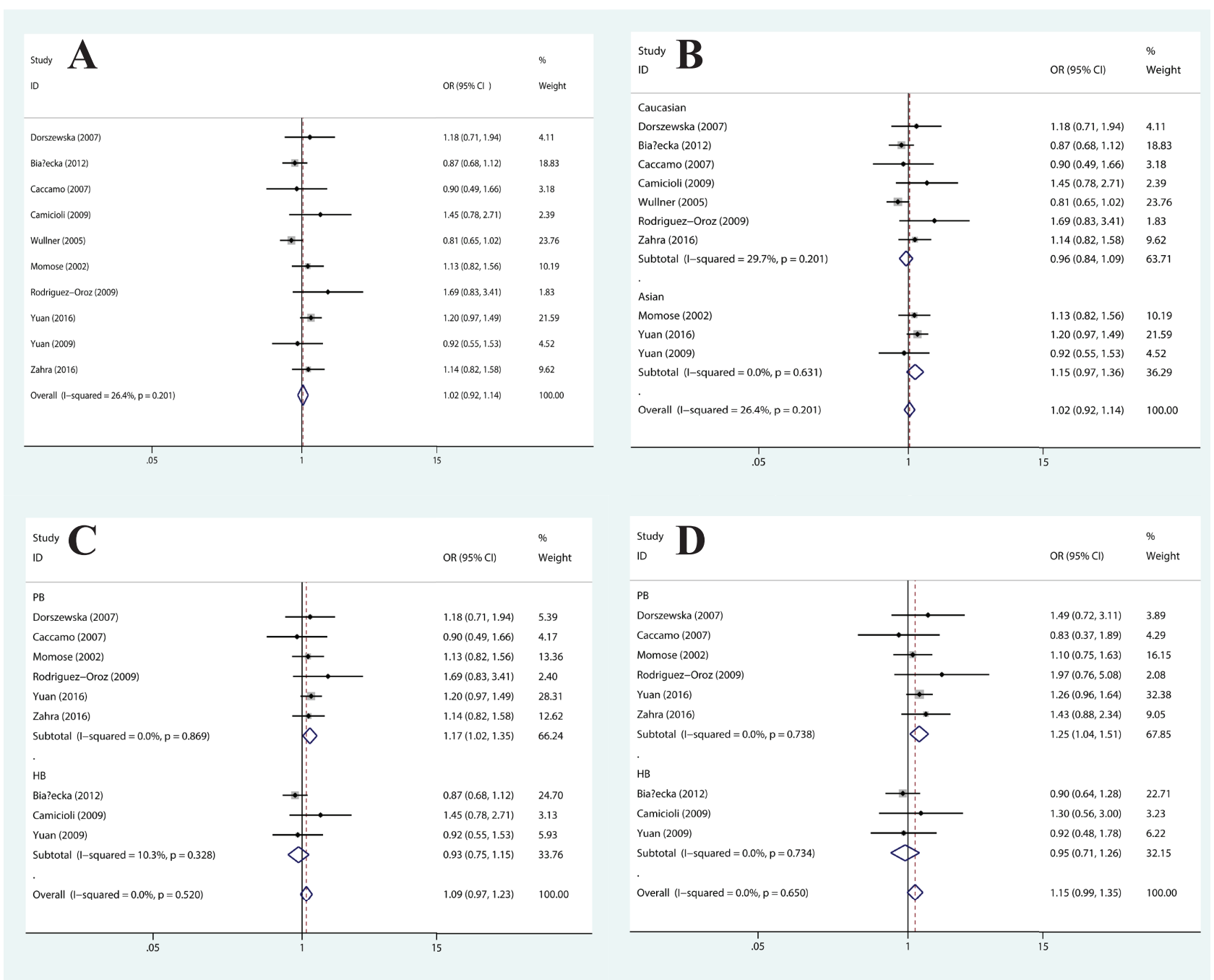

Figure 3: Forest plot of the association between MTHFR A1298C polymorphism and PD susceptibility: (A) allelic genetic model in the overall populations; (B) allelic genetic model, stratified by ethnicity; (C) allelic and (D) co-dominant genetic model, stratified by source of control.

\subsection{MTHFR A1298C and PD Susceptibility}

With regard to MTHFR A1298C polymorphism, the findings, on the basis of all of the involved research works, did not provide any proof of a link between MTHFR A1298C polymorphism and PD risk in any of the genetic framework in the population, in general (Figure 3A). For the stratified analysis in accordance with ethnicity, no substantial link in any genetic models in Caucasians or Asians (Figure 3B) was discovered. In the subgroup analysis in accordance with the source of controls, the significantly augmented susceptibility of PD was discovered in the allelic genetic framework ( $\mathrm{C}$ vs. A: $\mathrm{OR}=1.17,95 \% \mathrm{CI}=1.02-$ 1.35, $\mathrm{P}=0.029$ ), co-dominant genetic model (CA vs. AA: $\mathrm{OR}=1.25,95 \% \mathrm{CI}=1.04-1.51, \mathrm{P}=0.016)$, and dominant genetic model (TT+TC vs. CC: $\mathrm{OR}=1.25,95 \% \mathrm{CI}=1.05-1.49, \mathrm{P}=0.014$ ) in the population-based study (Figure 3C and 3D). Table 3 provides the summary of the findings of comparisons.

\subsection{MTHFR A2756G and PD Susceptibility}

In terms of MTHFR A2756G polymorphism, there was statistically significant association discovered in the co-dominant genetic model (GG vs. $\mathrm{AA}$ : $\mathrm{OR}=1.86,95 \% \mathrm{CI}=1.02-3.37$, $\mathrm{P}=0.042$ ) and recessive genetic model ( $\mathrm{GG}$ vs. $\mathrm{AA}+\mathrm{AG}$ : $\mathrm{OR}=1.90,95 \% \mathrm{CI}=1.06-3.41, \mathrm{P}=0.031)$ in the overall population (Figure 4A and 4B). With regard to the subgroup analysis in accordance with ethnicity, we found no substantial link in any genetic models in Caucasians or Asians. Additionally, in the subgroup analysis in accordance with the source of controls, MTHFR A2756G polymorphism was found to be linked to the increased susceptibility of PD 
Table 3: Summary ORs and $95 \% \mathrm{Cl}$ of the association between $\mathrm{A} 1298 \mathrm{C}$ polymorphism and Parkinson disease susceptibility.

\begin{tabular}{|c|c|c|c|c|c|c|c|c|}
\hline \multirow{2}{*}{ Genetic models } & \multirow{2}{*}{ Study subjects } & \multirow{2}{*}{$\begin{array}{l}\text { No. of } \\
\text { studies }\end{array}$} & \multirow{2}{*}{ OR $(95 \% \mathrm{Cl})$} & \multirow[t]{2}{*}{$p$-meta } & \multicolumn{3}{|c|}{ Test of heterogeneity } & \multirow{2}{*}{ Test of Egger's } \\
\hline & & & & & $I^{2}(\%)$ & $p$-value & Model & \\
\hline \multirow[t]{5}{*}{ C vs. A } & Overall & 10 & $1.02(0.92-1.14)$ & 0.652 & 26.4 & 0.201 & $\mathrm{~F}$ & 0.275 \\
\hline & Asian & 3 & $1.15(0.97-1.36)$ & 0.115 & 0 & 0.631 & $\mathrm{~F}$ & \\
\hline & Caucasian & 7 & $0.96(0.84-1.09)$ & 0.503 & 29.7 & 0.201 & $\mathrm{~F}$ & \\
\hline & PB & 6 & $1.17(1.02-1.35)$ & 0.029 & 0 & 0.869 & $\mathrm{~F}$ & \\
\hline & $\mathrm{HB}$ & 3 & $0.93(0.75-1.15)$ & 0.515 & 10.3 & 0.328 & $\mathrm{~F}$ & \\
\hline \multirow[t]{5}{*}{ CA vs. AA } & Overall & 10 & $1.11(0.97-1.28)$ & 0.144 & 0 & 0.608 & $\mathrm{~F}$ & 0.499 \\
\hline & Asian & 3 & $1.17(0.95-1.45)$ & 0.131 & 0 & 0.638 & $\mathrm{~F}$ & \\
\hline & Caucasian & 7 & $1.06(0.88-1.28)$ & 0.542 & 0 & 0.439 & $\mathrm{~F}$ & \\
\hline & PB & 6 & $1.25(1.04-1.51)$ & 0.016 & 0 & 0.738 & $\mathrm{~F}$ & \\
\hline & $\mathrm{HB}$ & 3 & $0.95(0.71-1.26)$ & 0.703 & 0 & 0.734 & $\mathrm{~F}$ & \\
\hline \multirow[t]{5}{*}{ CC vs. AA } & Overall & 10 & $0.93(0.72-1.19)$ & 0.557 & 0 & 0.491 & $\mathrm{~F}$ & 0.121 \\
\hline & Asian & 3 & $1.21(0.75-1.94)$ & 0.437 & 0 & 0.830 & $\mathrm{~F}$ & \\
\hline & Caucasian & 7 & $0.83(0.62-1.13)$ & 0.237 & 5.4 & 0.386 & $\mathrm{~F}$ & \\
\hline & PB & 6 & $1.24(0.86-1.79)$ & 0.251 & 0 & 0.975 & $\mathrm{~F}$ & \\
\hline & $\mathrm{HB}$ & 3 & $0.85(0.52-1.40)$ & 0.527 & 6.1 & 0.345 & $\mathrm{~F}$ & \\
\hline \multirow[t]{5}{*}{$C C+C A$ vs. $A A$} & Overall & 10 & $1.08(0.95-1.23)$ & 0.261 & 11.5 & 0.337 & $\mathrm{~F}$ & 0.378 \\
\hline & Asian & 3 & $1.18(0.97-1.44)$ & 0.107 & 0 & 0.611 & $\mathrm{~F}$ & \\
\hline & Caucasian & 7 & $1.01(0.84-1.20)$ & 0.942 & 23.4 & 0.250 & $\mathrm{~F}$ & \\
\hline & PB & 6 & $1.25(1.05-1.49)$ & 0.014 & 0 & 0.757 & $\mathrm{~F}$ & \\
\hline & $\mathrm{HB}$ & 3 & $0.93(0.71-1.22)$ & 0.603 & 0 & 0.505 & $\mathrm{~F}$ & \\
\hline \multirow[t]{5}{*}{$C C$ vs. $A A+A C$} & Overall & 10 & $0.88(0.69-1.12)$ & 0.310 & 0 & 0.726 & $\mathrm{~F}$ & 0.095 \\
\hline & Asian & 3 & $1.15(0.72-1.84)$ & 0.561 & 0 & 0.873 & $\mathrm{~F}$ & \\
\hline & Caucasian & 7 & $0.80(0.60-1.06)$ & 0.124 & 0 & 0.656 & $\mathrm{~F}$ & \\
\hline & PB & 6 & $1.09(0.76-1.54)$ & 0.642 & 0 & 0.973 & $\mathrm{~F}$ & \\
\hline & $\mathrm{HB}$ & 3 & $0.87(0.54-1.41)$ & 0.574 & 0 & 0.427 & $\mathrm{~F}$ & \\
\hline
\end{tabular}

Abbreviations: Bold values indicate statistically significant results; OR, Odds ratio; $\mathrm{Cl}$, Confidence interval; $p$-meta, $p$-value of pooled effect; R, Random-effect model; F, Fixed-effect model; NA, Not available.

in the co-dominant genetic model (GG vs. AA: $\mathrm{OR}=2.22$, 95\% CI=1.10-4.49, $\mathrm{P}=0.027)$ and recessive genetic model (GG vs. $\mathrm{AA}+\mathrm{AG}$ : $\mathrm{OR}=2.29,95 \% \mathrm{CI}=1.15-4.56, \mathrm{P}=0.018$ ) in the population-based study (Figure 4C and 4D). Table 4 presents the summary findings of comparisons.

\subsection{Sensitivity analysis}

For the purpose of assessing the stability of the findings of the meta-analysis, we carried out a sensitivity analysis with the help of the sequentially excluded separate research works. The results, having statistical similarity, were attained subsequent to the sequential exclusion of all studies (Figure 5).

\subsection{Publication bias}

The evaluation of the publication bias was carried out in accordance with the Begg's funnel plots and Egger's test. None of the shapes of the funnel plots indicated any proof of significant asymmetry (Figure 6). Nevertheless, the Egger's test yielded no proof suggesting publication bias. Moreover, the key results as presented in Table 2-4.

\section{Discussion}

Parkinson's disease (PD) is termed as a frequently found neurodegenerative illness that symptoms worsened gradually, ultimately impacting the quality of life of patients. As fully acknowledged, PD is termed as a multifactorial illness, which is a result of intricate gene-gene and 
Table 4: Summary ORs and $95 \% \mathrm{Cl}$ of the association between A2756G polymorphism and Parkinson disease susceptibility.

\begin{tabular}{|c|c|c|c|c|c|c|c|c|}
\hline \multirow{2}{*}{ Genetic models } & \multirow{2}{*}{ Study subjects } & \multirow{2}{*}{$\begin{array}{l}\text { No. of } \\
\text { studies }\end{array}$} & \multirow{2}{*}{ OR $(95 \% \mathrm{Cl})$} & \multirow[t]{2}{*}{$p$-meta } & \multicolumn{3}{|c|}{ Test of heterogeneity } & \multirow{2}{*}{ Test of Egger's } \\
\hline & & & & & $I^{2}(\%)$ & $p$-value & Model & \\
\hline \multirow[t]{5}{*}{ G vs. A } & Overall & 4 & $1.09(0.90-1.33)$ & 0.373 & 0 & 0.699 & $\mathrm{~F}$ & 0.748 \\
\hline & Asian & 2 & $1.09(0.88-1.35)$ & 0.428 & 0 & 0.687 & $\mathrm{~F}$ & \\
\hline & Caucasian & 2 & $1.11(0.68-1.79)$ & 0.683 & 21.0 & 0.260 & $\mathrm{~F}$ & \\
\hline & PB & 3 & $1.13(0.88-1.44)$ & 0.343 & 0 & 0.527 & $\mathrm{~F}$ & \\
\hline & $\mathrm{HB}$ & 1 & $1.04(0.75-1.44)$ & 0.818 & NA & NA & $\mathrm{F}$ & \\
\hline \multirow[t]{5}{*}{ GA vs. $A A$} & Overall & 4 & $0.96(0.75-1.23)$ & 0.742 & 0 & 0.943 & $\mathrm{~F}$ & 0.406 \\
\hline & Asian & 2 & $0.97(0.74-1.28)$ & 0.852 & 0 & 0.747 & $\mathrm{~F}$ & \\
\hline & Caucasian & 2 & $0.90(0.51-1.59)$ & 0.711 & 0 & 0.642 & $\mathrm{~F}$ & \\
\hline & PB & 3 & $0.92(0.67-1.27)$ & 0.614 & 0 & 0.892 & $\mathrm{~F}$ & \\
\hline & $\mathrm{HB}$ & 1 & $1.02(0.69-1.51)$ & 0.921 & NA & NA & $\mathrm{F}$ & \\
\hline \multirow[t]{5}{*}{ GG vs. AA } & Overall & 4 & $1.86(1.02-3.37)$ & 0.042 & 0 & 0.525 & $\mathrm{~F}$ & 0.943 \\
\hline & Asian & 2 & $1.76(0.93-3.32)$ & 0.084 & 0 & 0.408 & $\mathrm{~F}$ & \\
\hline & Caucasian & 2 & $2.53(0.45-14.21)$ & 0.292 & 40.3 & 0.195 & $\mathrm{~F}$ & \\
\hline & PB & 3 & $2.22(1.10-4.49)$ & 0.027 & 0 & 0.450 & $\mathrm{~F}$ & \\
\hline & $\mathrm{HB}$ & 1 & $1.20(0.39-3.69)$ & 0.744 & NA & NA & $\mathrm{F}$ & \\
\hline \multirow[t]{5}{*}{$G G+G A$ vs. $A A$} & Overall & 4 & $1.02(0.80-1.30)$ & 0.856 & 11.5 & 0.887 & $\mathrm{~F}$ & 0.582 \\
\hline & Asian & 2 & $1.03(0.79-1.35)$ & 0.827 & 0 & 0.987 & $\mathrm{~F}$ & \\
\hline & Caucasian & 2 & $0.99(0.57-1.73)$ & 0.972 & 23.4 & 0.430 & $\mathrm{~F}$ & \\
\hline & PB & 3 & $1.02(0.75-1.38)$ & 0.919 & 0 & 0.727 & $\mathrm{~F}$ & \\
\hline & $\mathrm{HB}$ & 1 & $1.03(0.70-1.52)$ & 0.870 & NA & NA & $\mathrm{F}$ & \\
\hline \multirow[t]{5}{*}{ GG vs. $A A+A G$} & Overall & 4 & $1.90(1.06-3.41)$ & 0.031 & 0 & 0.518 & $\mathrm{~F}$ & 0.933 \\
\hline & Asian & 2 & $1.79(0.96-3.35)$ & 0.066 & 0 & 0.366 & $\mathrm{~F}$ & \\
\hline & Caucasian & 2 & $2.62(0.47-14.66)$ & 0.274 & 36.7 & 0.209 & $\mathrm{~F}$ & \\
\hline & PB & 3 & $2.29(1.15-4.56)$ & 0.018 & 0 & 0.472 & $\mathrm{~F}$ & \\
\hline & $\mathrm{HB}$ & 1 & $1.20(0.39-3.62)$ & 0.752 & NA & NA & $\mathrm{F}$ & \\
\hline
\end{tabular}

Abbreviations: Bold values indicate statistically significant results; $\mathrm{OR}$, Odds ratio; $\mathrm{Cl}$, Confidence interval; $p$-meta, $p$-value of pooled effect; R, Random-effect model; F, Fixed-effect model; NA, Not available.

gene-environment contacts [37]. Even though the therapy steps have advanced continuously for controlling symptoms, so far no methodology exists for the prevention of the incidence of PD. The latest observations have shed light on the involving homocysteine (Hcy) in the pathogenesis of PD $[6,8,38]$. There are some research works that have discovered an augmented incidence of the illness in those subjects, who carry the MTHFR genotype and identified a major role for Hcy in the promotion of the susceptibility and growth of PD; on the other hand, other research works reached the contrary conclusion [11, 12, 24, 26, 34].

The MTHFR gene is located on chromosome $1 \mathrm{p} 36.3$ spanning more than $20 \mathrm{~kb}$ and containing a noncoding exon as well as 11 coding exons [39]. In addition, the encoded enzyme catalyzes the conversion of 5,10-methylenetetrahydrofolate, a carbon donor in nucleotide biosynthesis, to 5-methyltetrahydrofolate, the key form of circu- latory folate, together with providing a methyl group for the re-methylation of Hcy back to methionine [8]. Genetic mutations in the MTHFR gene have the potential to causing the autosomal recessive homocystinuria because of the MTHFR shortage. In addition, gene variants have been extensively studied in lots of illness, which also include PD.

Even though the augmented number of case-control research works studied the link between MTHFR genetic polymorphism and PD risk; however, the findings remain controversial. In the year 2014, a large case-control study by Liao was conducted for the purpose of investigating the function of the MTHFR genetic polymorphism in PD susceptibility and the results demonstrated that the MTHFR C677T genetic polymorphism had an association with the decreased PD susceptibility [26]. Fong et al. carried out study for the discovery of the link of MTHFR genetic polymorphism with PD susceptibility; the results shed light on 


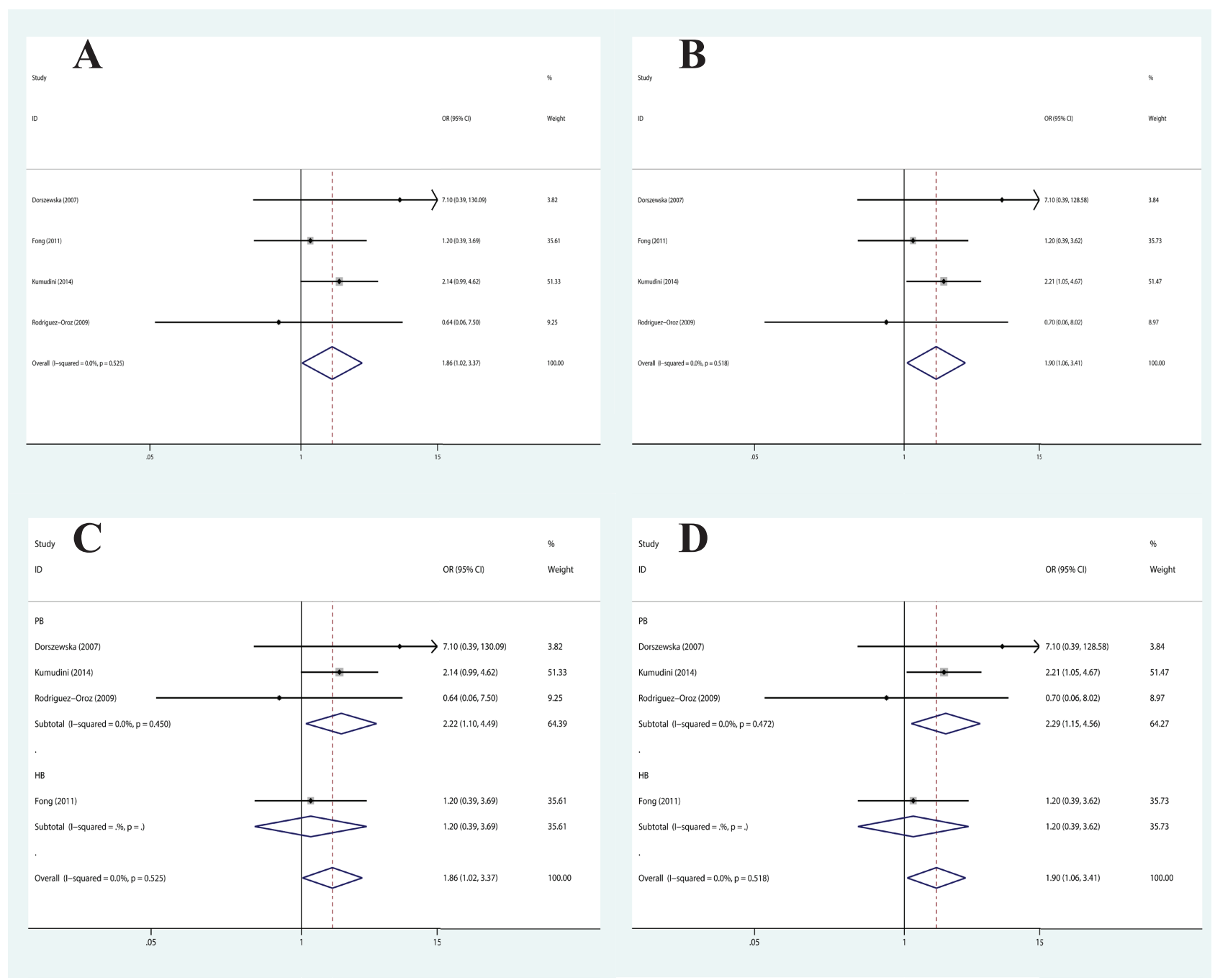

Figure 4: Forest plot of the association between MTHFR A2756G polymorphism and PD susceptibility: (A) co-dominant and (B) recessive genetic model in the overall populations; (C) co-dominant and (D) recessive genetic model, stratified by source of control.

the fact that the augmented PD susceptibility is expected to have more significance in the carriers that have the polymorphisms of MTHFR gene [26].

The present meta-analysis is carried out on the basis of the systematic review, which follows the PRISMA guidelines. The robustness of a systematic review involves including the papers that are not based on the selection of authors but the number of papers retrieved from electronic databases. That is why it depends not only on the quality but also the specimen size of investigations involved in the systematic review. Furthermore, a meta-analysis is termed as a methodology pooling the effect sizes of the current scientific literature. A meta-analysis can be carried out on two or more papers. Therefore, it is of great significance to perform a meta-analysis of all of the qualified research works for the clarification of the impacts of the MTHFR genetic polymorphism with PD susceptibility.
As illustrated by the current meta-analysis, the A2756G polymorphism in MTHFR gene had an association with an increased risk of PD. However, the C677T and A1298C polymorphisms are not likely to perform a significant function in the risk to PD. Moreover, the meta-analysis carried out by Liu et al. in the year 2018 demonstrated that MTHFR (C677T and A1298C) polymorphism is likely to have an association with the augmented PD susceptibility, which was different from our result [40].

The possible constraints of the meta-analysis require consideration. At first, the specimen in this meta-analysis was small in size, which was likely to give rise to the partiality of the findings in the course of the evaluation of the link between MTHFR genetic polymorphisms and risk to PD. Second, the genuine data in some of the research works was deficient that was likely to constrain enough statistical power for the evaluation of the underlying impacts of 

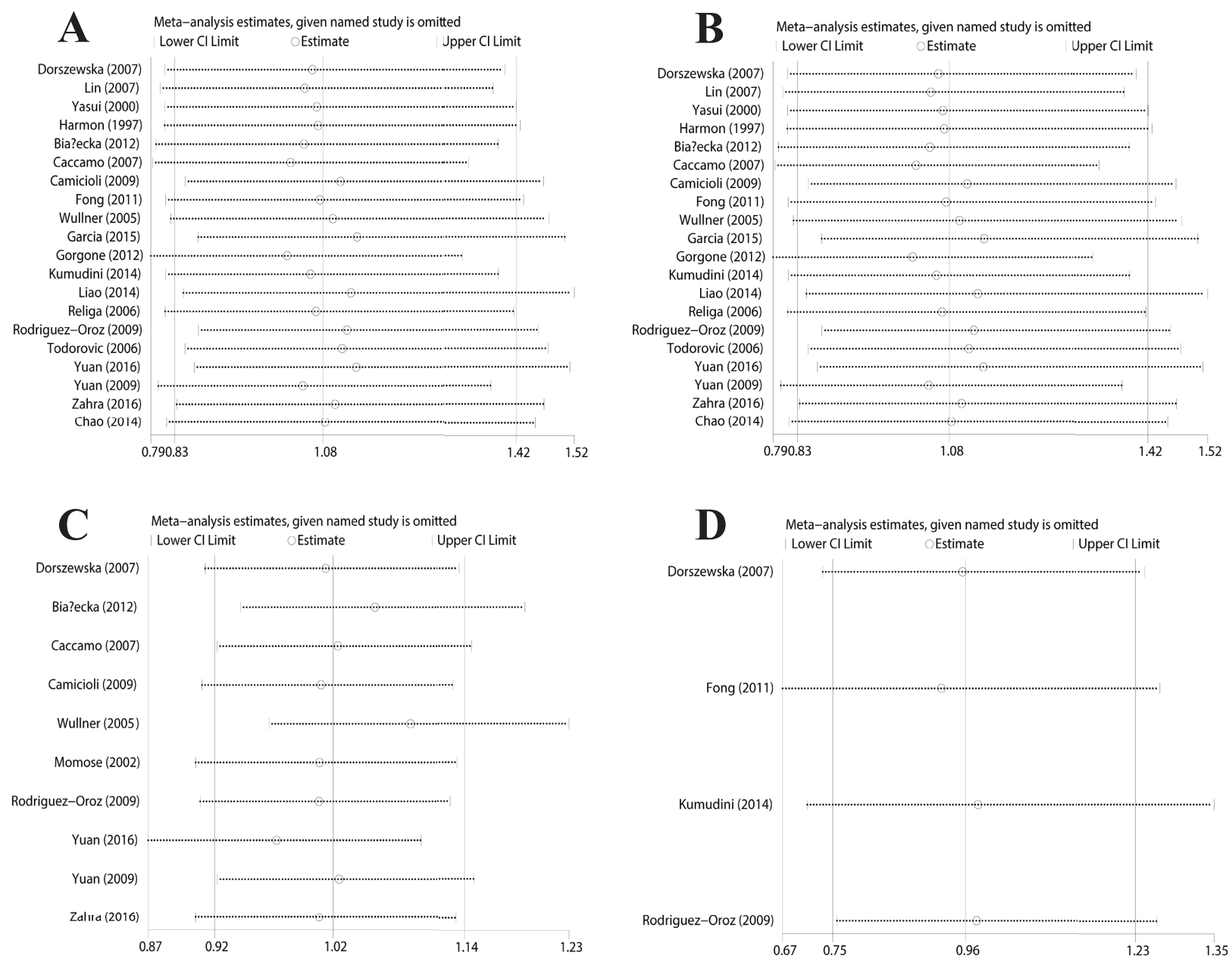

Figure 5: Sensitivity analysis of studies on MTHFR genetic polymorphism and PD: (A) allelic and (B) co-dominant genetic model for C677T polymorphism; (C) allelic genetic model for A1298C polymorphism; (D) allelic genetic model for A2756G polymorphism.

gene-gene and gene-environment contacts on the growth of PD. Third, the meta-analysis just counts on the research works that were published in English or Chinese that are likely to give rise to the selection partiality in the accumulated findings. Fourthly, a substantial difference exists in numbers between PD cases and controls that is likely to exert an influence on the dependability of our findings. Based on the above reasons, the pooled estimates of our meta-analysis require careful interpretation.
To conclude, the current meta-analysis illustrated the fact that the MTHFR A2756G genetic polymorphism confers susceptibility to PD, but no link was observed to exist between the C677T and A1298C polymorphisms and PD susceptibility. More efficiently formulated investigations, which have larger specimens, are required for the purpose of clarifying the link of the MTHFR genetic polymorphism with PD risk. 


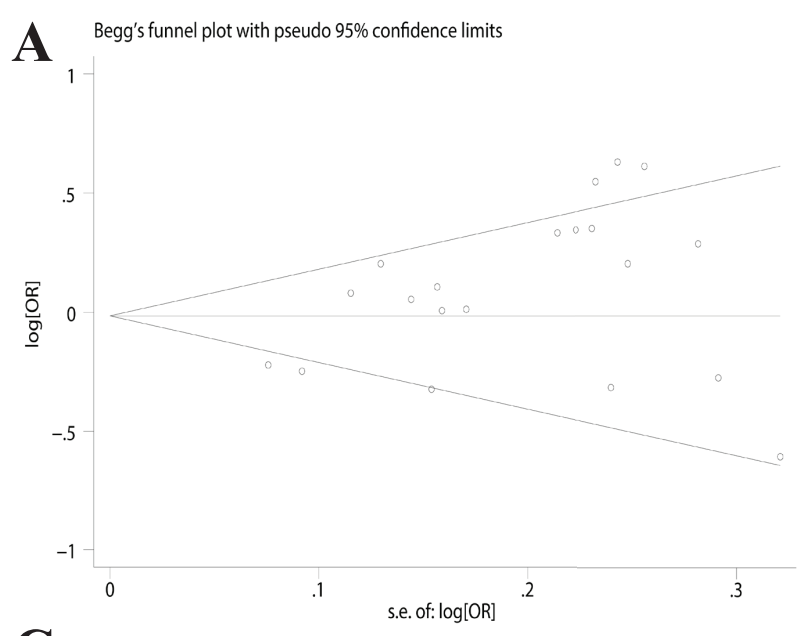

C

Begg's funnel plot with pseudo $95 \%$ confidence limits
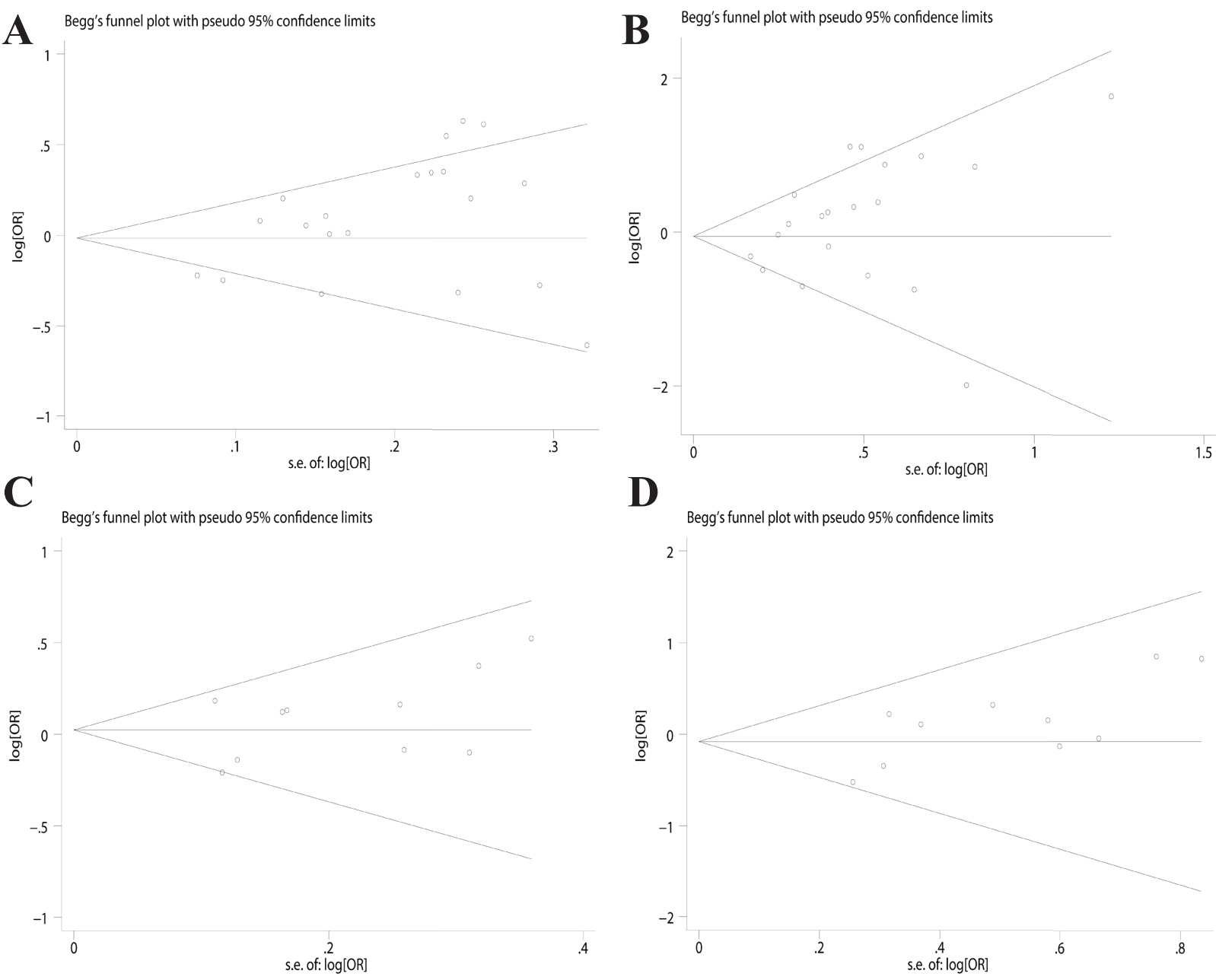

D

Begg's funnel plot with pseudo 95\% confidence limits

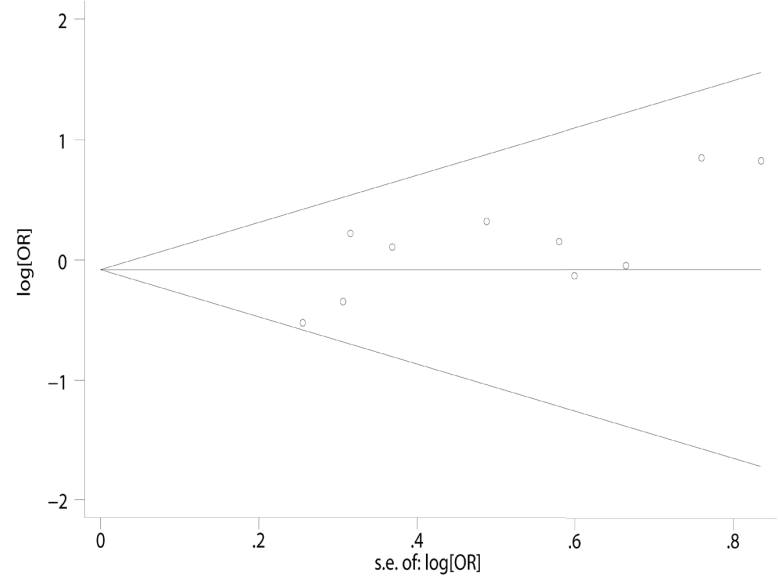

Figure 6: Begg's funnel plots of publication bias for the association between MTHFR genetic polymorphism and PD: (A) allelic and (B) codominant genetic model for C677T polymorphism; (C) allelic and (D) co-dominant genetic model for A1298C polymorphism.

Conflict of interest: The authors declare no existence of any conflicting interest.

\section{References}

[1] de Lau LM, Breteler MM. Epidemiology of Parkinson's disease. Lancet Neurol. 2006;5:525-535

[2] Elbaz A, Carcaillon L, Kab S, Moisan F. Epidemiology of Parkinson's disease. Rev Neurol (Paris). 2016;172:14-26

[3] Berganzo K, Tijero B, Gonzalez-Eizaguirre A, et al. Motor and non-motor symptoms of Parkinson's disease and their impact on quality of life and on different clinical subgroups. Neurologia. 2016;31:585-591

[4] reenamyre JT, Hastings TG. Biomedicine. Parkinson's--divergent causes, convergent mechanisms. Science. 2004;304:1120-1122
[5] Tiwari PC, Pal R. The potential role of neuroinflammation and transcription factors in Parkinson disease. Dialogues Clin Neurosci. 2017;19:71-80

[6] Bonetti F, Brombo G, Zuliani G. The relationship between hyperhomocysteinemia and neurodegeneration.

Neurodegener Dis Manag. 2016;6:133-145

[7] Kruman, II, Culmsee C, Chan SL, et al. Homocysteine elicits a DNA damage response in neurons that promotes apoptosis and hypersensitivity to excitotoxicity. J Neurosci. 2000;20(18):6920-6926

[8] Moretti R, Caruso P. The Controversial Role of Homocysteine in Neurology: From Labs to Clinical Practice. Int J Mol Sci. 2019;20. pii: E231

[9] de Lau LM, Koudstaal PJ, van Meurs JB, Uitterlinden AG, Hofman A, Breteler MM. Methylenetetrahydrofolate reductase C677T genotype and PD. Ann Neurol. 2005;57:927-930

[10] Gorgone G, Curro M, Ferlazzo N, et al. Coenzyme Q10, hyperhomocysteinemia and MTHFR C677T polymorphism in levodopa-treated Parkinson's disease patients. Neuromolecular Med. 2012;14:84-90 
[11] Liao Q, Li NN, Mao XY, et al. MTHFR C677T variant reduces risk of sporadic Parkinson's disease in ethnic Chinese. Acta Neurol Scand. 2014;130:e30-34

[12] Yuan L, Song Z, Deng X, Xiong W, Yang Z, Deng H. Association of the MTHFR rs1801131 and rs1801133 variants in sporadic Parkinson's disease patients. Neurosci Lett. 2016;616:26-31

[13] Stroup DF, Berlin JA, Morton SC, et al. Meta-analysis of observational studies in epidemiology: a proposal for reporting. Meta-analysis Of Observational Studies in Epidemiology (MOOSE) group. JAMA. 2000;283:2008-2012

[14] Zintzaras E, loannidis JP. HEGESMA: genome search meta-analysis and heterogeneity testing. Bioinformatics. 2005;21:3672-3673

[15] Mantel N, Haenszel W. Statistical aspects of the analysis of data from retrospective studies of disease. J Natl Cancer Inst. 1959;22:719-748

[16] DerSimonian R, Laird N. Meta-analysis in clinical trials revisited. Contemp Clin Trials. 2015;45:139-145

[17] Begg CB, Mazumdar M. Operating characteristics of a rank correlation test for publication bias. Biometrics. 1994;50:1088-1101

[18] Egger M, Davey Smith G, Schneider M, Minder C. Bias in meta-analysis detected by a simple, graphical test. BMJ. 1997;315:629-634

[19] Dorszewska J1, Florczak J, Rozycka A, et al. Oxidative DNA damage and level of thiols as related to polymorphisms of MTHFR, MTR, MTHFD1 in Alzheimer's and Parkinson's diseases. Acta Neurobiol Exp (Wars). 2007;67:113-129

[20] Lin JJ, Yueh KC, Liu CS, Liu JT, Lin SZ. 5,10-methylenetetrahydrofolate reductase $\mathrm{C677T}$ gene polymorphism can influence age at onset of Parkinson's disease. Acta Neurol Taiwan. 2007;16:150-157

[21] Yasui K, Kowa H, Nakaso K, et al. Plasma homocysteine and MTHFR C677T genotype in levodopa-treated patients with PD. Neurology. 2000;55:437-440

[22] Harmon DL, Ramsbottom D, Whitehead AS, et al. The thermolabile variant of 5,10-methylenetetrahydrofolate reductase is not associated with Parkinson's disease. J Neurol Neurosurg Psychiatry. 1997;62:671

[23] Bialecka M, Kurzawski M, Roszmann A, et al. Association of COMT, MTHFR, and SLC19A1(RFC-1) polymorphisms with homocysteine blood levels and cognitive impairment in Parkinson's disease. Pharmacogenet Genomics. 2012;22:716-724

[24] Caccamo D, Gorgone G, Currò M, et al. Effect of MTHFR Polymorphisms on Hyperhomocysteinemia in Levodopa-treated Parkinsonian Patients. Neuromolecular Med. 2007;9:249-254

[25] Camicioli RM, Bouchard TP, Somerville MJ. Homocysteine is not associated with global motor or cognitive measures in nondemented older Parkinson's disease patients. Mov Disord. 2009;24:176-182
[26] Fong CS, Shyu HY, Shieh JC, et al. Association of MTHFR, MTR, and MTRR polymorphisms with Parkinson's disease among ethnic Chinese in Taiwan. Clin Chim Acta. 2011;412:332-338

[27] Fregni F, DaSilva D, Potvin K, et al. Treatment of chronic visceral pain with brain stimulation. Ann Neurol. 2005;58:971-972

[28] García S, Coral-Vázquez RM, Gallegos-Arreola MP, et al. Association of the rs1801133 variant in the MTHFR gene and sporadic Parkinson's disease. Folia Neuropathol. 2015;53:24-28

[29] Kumudini N, Uma A, Naushad SM, Mridula R, Borgohain R, Kutala VK. Association of seven functional polymorphisms of one-carbon metabolic pathway with total plasma homocysteine levels and susceptibility to Parkinson's disease among South Indians. Neurosci Lett. 2014;568:1-5

[30] Religa D, Czyzewski K, Styczynska M, et al. Hyperhomocysteinemia and methylenetetrahydrofolate reductase polymorphism in patients with Parkinson's disease. Neurosci Lett. 2006;404:56-60

[31] Rodriguez-Oroz MC, Lage PM, Sanchez-Mut J, et al. Homocysteine and cognitive impairment in Parkinson's disease: a biochemical, neuroimaging, and genetic study. Mov Disord. 2009;24:1437-1444

[32] Todorović Z, Džoljić E, Novaković I, et al. Homocysteine serum levels and MTHFR C677T genotype in patients with Parkinson's disease, with and without levodopa therapy. J Neurol Sci. 2006;248:56-61

[33] Yuan R-Y, Sheu J-J, Yu J-M, et al. Methylenetetrahydrofolate reductase polymorphisms and plasma homocysteine in levodopa-treated and non-treated Parkinson's disease patients. J Neurol Sci. 2009;287:64-68

[34] Zahra C, Tabone C, Camilleri G, Felice AE, Farrugia R, Bezzina Wettinger S. Genetic causes of Parkinson's disease in the Maltese: a study of selected mutations in LRRK2, MTHFR, QDPR and SPR. BMC Med Genet. 2016; 17: 65

[35] Ning C, Liang S, Hui-Yan Y, et al. Association between methylenetetrahydrofolate reductase gene $\mathrm{C677T}$ polymorphism and Parkinson's disease combined with hyperhomocysteinemia. Chin J Geriatr. 2014; 33: 121-125

[36] Momose Y, Murata M, Kobayashi K, et al. Association studies of multiple candidate genes for Parkinson's disease using single nucleotide polymorphisms. Ann Neurol. 2002;51:133-136

[37] Warner TT, Schapira AH. Genetic and environmental factors in the cause of Parkinson's disease. Ann Neurol. 2003;53:S16-23; discussion S23-25

[38] Sharma M, Tiwari M, Tiwari RK. Hyperhomocysteinemia: Impact on Neurodegenerative Diseases. Basic Clin Pharmacol Toxicol. 2015;117:287-296

[39] Prasad AN, Rupar CA, Prasad C. Methylenetetrahydrofolate reductase (MTHFR) deficiency and infantile epilepsy. Brain Dev. 2011;33:758-769

[40] Liu L, Zhang L, Guo L, et al. MTHFR C677T and A1298C polymorphisms may contribute to the risk of Parkinson's disease: A meta-analysis of 19 studies. Neurosci Lett. 2018;662:339-345 